\title{
CONFERENCE IN HONOUR OF THE 65TH BIRTHDAY OF \\ PROFESSOR DAVID WILKIE
}

Heriot-Watt University, Edinburgh, 20-21 March 2000

\section{Announcement and call for papers}

A conference is being held in honour of Professor David Wilkie's 65th birthday. The conference will have four sessions on the following topics:

- Asset models;

- Asset-liability models;

- Mortality and morbidity models;

- Actuarial science.

Each session will be led by a keynote speaker, followed by contributed papers and discussion.

Scientific Committee: Hans Bühlmann (ETH Zurich), Andrew Cairns (Heriot-Watt), Angus Macdonald (Heriot-Watt), Howard Waters (HeriotWatt).

The conference fee is GBP 115. Accommodation is available on campus at Heriot-Watt University, or in the city of Edinburgh.

Please register intention to attend the conference by contacting one of the addresses or numbers below. Interested speakers are invited to participate in the conference and to submit a paper for presentation. They are asked to submit an abstract of their paper by 31 December 1999.

\author{
ANGUS MACDONALD \\ Department of Actuarial Mathematics and Statistics \\ Heriot-Watt University, Edinburgh, \\ EH14 4AS, United Kingdom \\ Enquiries: wilkiefest@ma.hw.ac.uk \\ Tel. $+44(0) 1314513717$ \\ Fax + 44(0)131 4513249
}

